\title{
The Study of Damping Strategy Based on Civil Engineering Structures
}

\author{
Mingyu Wang1 \\ Xijing University, Xi'an, 710123, China \\ e-mail: 2473712873@qq.com \\ Shidan He3 \\ Xijing University, Xi'an, 710123, China \\ e-mail: 315705804@qq.com
}

\author{
Xiaofang Li2 \\ Xijing University, Xi'an, 710123, China \\ line 4: e-mail: 563237924@qq.com
}

\begin{abstract}
Objective: Take some control measures to reduce and inhibit the dynamic response of the structure during the earthquake, strong winds and other dynamic loads, to enhance the dynamic stability of the structure, to improve the structural capacity to resist external vibration, so that it can meet the requirements of safety, serviceability, comfort. Methods: This paper takes damping strategy measures based on Civil engineering structures. Results: Intelligent control can effectively deal with factors including to nonlinear systems, time-varying, strong coupling, uncertainty, and it has become a promising civil structure control technology. Conclusion: damping strategy based on Civil engineering structures, can meet the requirements of safety, serviceability, comfort.The effect of vibration control of civil engineering structures with a variety of factors related to the structure and control system, including the environmental effects, structural characteristics.
\end{abstract}

Keywords-Damping strategy; civil engineering structures; intelligent control

\section{INTRODUCTION}

Structural vibration control refers to in a specific site of engineering structures, set up some sort of control device, or some organization, or some sub-structure or applied external force to change or adjust the dynamic characteristics or dynamic action structure to reduce structural vibration response of engineering technology. Structural vibration control is a new discipline. It's Objective is to take some control measures to reduce and inhibit the dynamic response of the structure during the earthquake, strong winds and other dynamic loads, to enhance the dynamic stability of the structure, to improve the structural capacity to resist external vibration,so that it can meet the requirements of safety, serviceability, comfort.

Development of structural vibration control technology has gone through several stages [1]: 1970s;

a) The establishment of concept phase, began in the

b) Research stage, mainly including theoretical research and experimental phase, began in the 1970s;

c) Application stage. A pilot project began in the 1980s. Application took control in different ways according to the different techniques and methods.

This article studies the structure of civil engineering structural vibration control principle, structure control method (passive control, active control, semi-active control, hybrid control and intelligent control), pointed out that the structure of control problems and solutions. I hope that by studying this article, can provide a reference work for the relevant personnel damping.

\section{STRUCTURAL VIBRATION CONTROL PRINCIPLE}

Based on A single degree of freedom system, the dynamic equilibrium equations for the earthquake is:

$$
m\left(\ddot{x}+\ddot{x}_{g}\right)+c x+F(x)=0
$$

The problem of structural vibration is reflect by the dynamic equilibrium equations. Reducing the seismic response of structures primarily is shown in the following areas:

a) Don't let seismic input, namely vibration absorber, which is to prevent earthquake. Currently implementing this approach still has considerable difficulty.

b) Let inertia force reduce. According to dynamics, the larger structural vibration period, the smaller the obtained acceleration. So we can achieve this aim by isolation methods.

c) Increase the damping structure, to reduce seismic effects of the structural member of the burden. However, usually it has a small damping structure itself. Steel itself damping ratio is about $2 \%$, about $5 \%$ of the concrete structure. So we should seek to increase the structural damping, which increase the number of dampers in addition to the main structure.

d) Artificially set some member, take advantage of these additional components plastic deformation energy consumption to protect the integrity of the main structure.

e) Further add structure in a mass - spring system, the equivalent of a tuner. However, the additional system itself suitable frequency, such that the movement direction of the additional mass may be opposite to the direction of movement of the block structure, thereby reducing the amplitude of the vibration of the structure, to achieve the purpose of shock absorption.

According Uang and Bertero proposed energy conservation relations [2], the above equation becomes the following kinetic energy equation:

$$
E=E_{k}+E_{s}+E_{h}
$$


$E-$ is the total energy input structure of earthquake excitation

$$
\begin{aligned}
& E_{k}-\text { is kinetic structure; } \\
& E_{s}-\text { is structure elastic strain energy; } \\
& E_{h}-\text { is structure inelastic deformation energy }
\end{aligned}
$$
dissipated;

Whether the structure can effectively resist earthquake damage without causing collapse, it is how to ensure that the seismic energy is absorbed by the other three consumed.

Damping control system is shown as Figure 1. We do the attachmen $F_{s}(x,>x)$ On the main structure. $F_{s}$ is designed to consume energy. Thus kinetic equation becomes:

$$
m \ddot{x}+c x+F(x)+F(x,>x)=-m \ddot{x}_{g}
$$

Corresponding to the energy equation is:

$$
E=E_{k}+E_{s}+E_{h}+E_{d}
$$

By structure control, increased energy dissipation term $E_{d}$ in right side of equation, greatly reduced kinetic energy structure, the elastic strain energy and inelastic deformation energy. Especially non-elastic deformation can protect the structure from earthquake damage incentives. This is the principle of Energy Dissipation of energy.

\section{DAMPING STRATEGY BASED ON CIVIL ENGINEERING STRUCTURES}

In general, structural vibration control method can be charged whether the system has an external energy input into a passive control, active control, semi-active control and hybrid control.

\section{A. passive control}

Structure passive control refers to the control device that does not require external energy input control. Its' characterization is isolation, energy dissipation and vibration absorbing vibration energy consumption and other technologies, to achieve the purpose of reducing the structural vibration response. Advantages of passive control are construct simple, low cost, easy to maintain, and not external energy support. Currently, the passive control devices which are widely used are:

\section{1) Base isolation system}

Base isolation is to set some kind of vibration energy dissipation means between the upper structure and foundation, to reduce the transmission of seismic energy upward portion, so as to achieve the purpose of reducing the vibration of the upper structure.

Isolation device must have three characteristics: a large deformation capacity; a sufficient initial stiffness and strength; providing greater damping, with great energy.

Base isolation can significantly reduce the vibration frequency structure in low-rise buildings and a rigid structure suitable for short periods. Due to the highfrequency seismic waves only effective isolation, therefore not applicable to high-rise buildings.

2) Energy dissipation system

Commonly used energy component are energy support and energy dissipation shear walls etc; commonly used damper are metal yielding dampers, friction dampers, viscoelastic dampers, viscous fluid dampers.

Metallic yield damper is made of mild steel or other metal materials made of soft forms of damping dampers. Structural vibration control mechanism is the part of the energy structural vibration by yielding metal hysteretic energy dissipated, so as to achieve the purpose of reducing the structural response.

Friction damper consisting essentially of metal (or other solid material) elements, these elements can slide between and the frictional force generated there. Structural vibration control mechanism is the part of the energy structural vibration damper element by friction between the energy dissipated, so as to achieve the purpose of reducing the structural response.

Viscoelastic dampers is constrained by a viscoelastic material and steel components. Vibration control mechanism is part of the energy structure by vibration damper viscoelastic material shear deformation energy dissipated, so as to achieve the purpose of reducing the structural response.

\section{3) Tuned damping system}

Common tuning damping systems are: tuned mass damper (TMD), tuned liquid damper (TLD), hydraulic vibration control system quality (HMS), etc.

Tuned mass damper is a small vibration system, which consists of mass, springs and dampers. Structural vibration control mechanism is: the original structural system due to joining the TMD, its dynamic characteristics changed. The original structure to withstand severe vibration and dynamic action, due to the inertia of the mass of TMD and the original structure of the force applied in the opposite direction, the damping also playing a role in energy, so that the vibration response of the original structure was significantly attenuated.

TMD has been widely used in civil engineering, typical applications for Japan's ChibaPort tower, which is shown as Fig .2.

Tuned liquid damper is water containers which is mounted on a structure and has a certain shape. Structural vibration control mechanism is: in the process of structural vibration, dynamic pressure vessel inertial force of water and waves generated by the vessel wall will constitute the structure of control, part of the energy at the same time, and will also be dissipated due to the vibration of the structure of water stickiness, so as to achieve the purpose of reducing the structural response.

\section{B. Active Control}

Some of the concepts of active control structure was first proposed by the Zuk [7]. Active Control is a need for external energy structure control technology. By structural response to external incentives and real-time monitoring, then in accordance with various control methods to calculate the control, and to the structure automatically adjusted by servo urging means for applying, making the structure in an external process has always been positioned 
in the vicinity of the initial state, so as to achieve to protect structures from the purpose of injury.

Active Control system block diagram is shown as Figure 3. It works as follows: dynamic response of the sensor monitoring structures and external stimuli, will monitor the information fed into the computer, the computer according to a given algorithm gives force to be applied to size. Finally, driven by the external energy source, the control system generates the force required. Advantages of active control is due to continuous change of control, and thus a very wide frequency control, can adapt to different external incentive to achieve excellent control effect, and can be very easily applied existing modern control theory and the latest research results.At present, the commonly used active control devices are [8]: active mass damper, active tendon system, active bracing system, active aerodynamic appendages control.

Active Control algorithm is one of the main research tasks Active Control System. Active Control algorithm aims to find the relationship between the actuator optimal or near-optimal control and the structure of state variables and parameters, in order to achieve real-time tracking and control. Currently, the algorithm often used are [9]: instantaneous optimal control algorithm, adaptive control algorithm, fuzzy control algorithms, predictive control, neural network control algorithm, sliding mode control, robust control.

Currently, there are some buildings successfully applied active control technology. Such as Tokyo, Japan built a 11-story building Kyobashi Seiwa, the building in 1989 offshore earthquake seismic displacement reaction is reduced by about 60 percent, hit by strong typhoon in 1990 , its wind-induced vibration acceleration response decreased by about $50 \%$.

The disadvantage is that the active control must have a fairly high-powered actuator mechanism and energy storage devices. Control algorithm requires the dynamic characteristics of the actual structure which is difficult to obtain accurate mathematical model based on the establishment of the precise structural vibration model, will undoubtedly drop in quality control, can cause serious instability control, accelerate the destruction of the building structure. This is also the main reason for the active control in the actual building structure rarely used.

\section{Semi-active control}

The so-called semi-active control requires only a small external energy input power, providing direct control, the control process depending on the structural response information or outside interference control method information. Semi-active control devices generally do not directly control the output, but to change the structure of the controlled stiffness and damping system parameters through the control device, below the parameter controls. Key semi-active control technology is semi-active control devices and control strategy, semi-active control strategy is a semi-active control technology of core issues.

In the field of civil engineering, semi-active control study began in 1983, Hrovat proposed application variable damping controller ideological civil engineering structures semi-active control [10]. Commonly used semi-active control system: variable stiffness system (AVS), a variable damping system (AVD), active tuned mass damper system parameters (STLD, STMD), controlled (ER or magnetorheological) fluid dampers (ER / MR damper), controllable friction isolation system.

\section{Hybrid Control}

Hybrid control is combination of active control and passive control. Hybrid control helps to reduce the constraints and limitations of a single control mode, to play active control and passive control of both advantages. The current active control technology applications, mostly through mixing control to achieve.On the relative size of the hybrid control in the role of active and passive control point of view, you can have two kinds of combinations. One is the master-slave mode, that is, in some controloriented, another control play a supporting role. The second is juxtaposed manner that two kinds of control operate independently.

Currently several more classic hybrid control means are: a hybrid control active mass damping (AMD) system and tuned mass damper (TMD) system or tuned liquid damper (TLD) combination; active control combined with damping energy mix control; active control with a combination of base isolation mixing control.

Active Control Technology Based on the structure of hybrid control technology, while the advantages of technology and control technology both passive structure active control, but its essence is still fully active control technology, still more external energy input. In recent years, the development of a new hybrid semi-active control and passive control of a combination of control technology, because it has the advantages of semi-active control and passive control, will have a higher reliability and availability

\section{E. Intelligent control}

Intelligent control structure including the use of intelligent control algorithms and intelligent drive or class 2 smart damping devices. When the structure encountered strong earthquake may enter non-linear. Carrying capacity and stiffness of structural members degraded. The actual structure model updating is a prominent problem of structural vibration control. Intelligent control algorithm in order to solve this problem and introduced. Intelligent control algorithm can not rely on precise structural model, or have a strong ability to learn and adjust approximation. The current structure of intelligent control algorithm are:

Fuzzy control algorithm. Fuzzy Control fuzzy logic is mainly through state output and control input, namely achieving regulate or control system is by fuzzy control rules.

Neural network control algorithms. Artificial neural network has a strong nonlinear approximation, selflearning and adaptive, data integration and parallel distributed processing capabilities. In multivariate, nonlinear systems identification, modeling and control has obvious advantages and applications. 


\section{F. Figures}

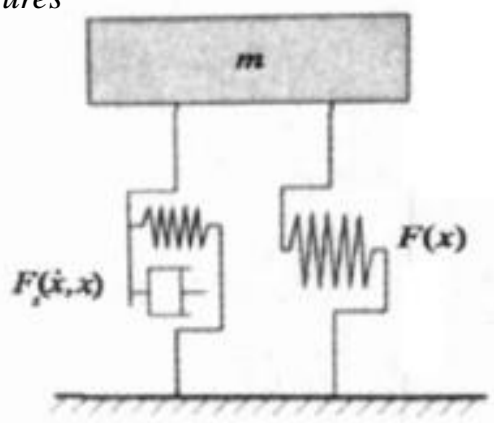

Figure 1. Diagram of vibration control structure

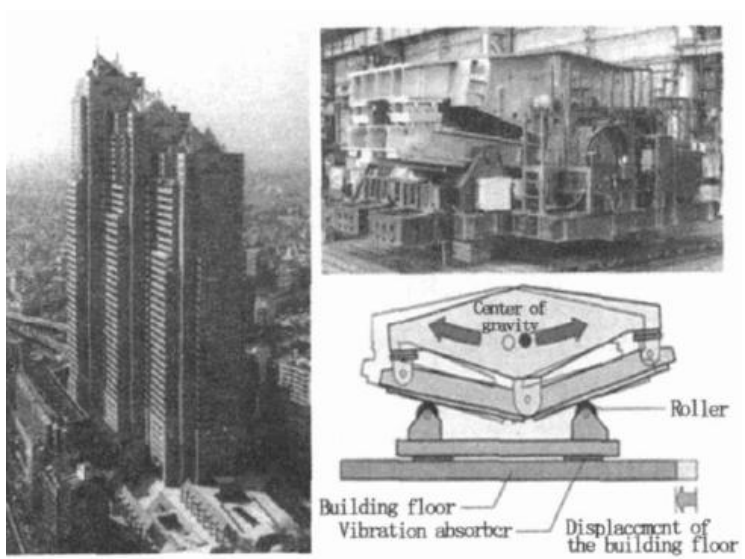

Figure 2. Application of TMD in Japan

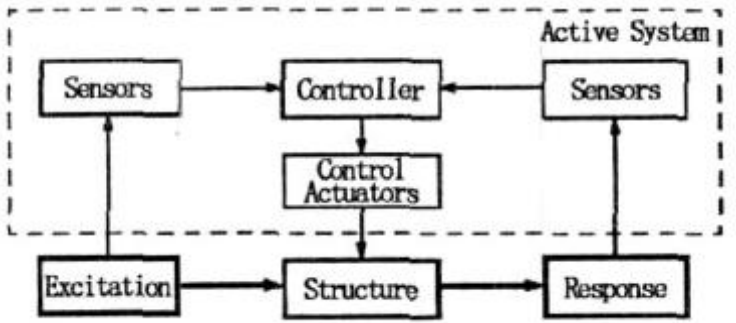

Figure 3. Block diagram of active control system

\section{CONCLUSIONS}

Control theory solves many of the control problems of complex systems, but in the civil structural vibration control applications there are still many problems, which is shown as follows:
1. Because the body structures are relatively huge, nearly unlimited freedom, even with a relatively accurate finite element modeling, structure control degrees of freedom is amazing, so there are some problems of mathematical modeling;

2. External load exists uncertain factors;

3. Signal sensor collected inevitable presence of noise pollution. Precision and observation area is inversely proportional to the observed sensor, it is possible due to unknown factors caused the observed overflow and spill control.

This article studies the structure of civil engineering structural vibration control principle, structure control method (passive control, active control, semi-active control, hybrid control and intelligent control), pointed out that the structure of control problems and solutions. I hope that by studying this article, can provide a reference work for the relevant personnel damping.

\section{REFERENCES}

[1] Uang C M,Bertero V V. "Use of Energy as a Design Criterion in Earthquake - Resistant Design" R. Report No. UCB/EERC 88/18.Berkeley,CA,USA: University of California, 1988.

[2] F. L. Zhou. "Engineering structural vibration control" M. Wuhan. Earthquake Press, 1997.

[3] S. Y. Xue, Q. Zhou,etc. "Vibration Control in the spatial structure of the application" C. Tenth Conference Proceedings spatial structure, Beijing, China Building Materials Industry Press, 2002. Pp. 561-567.

[4] Nielsen E J. V. "iscoelastic Damper Overview for Seismic and Wind Application " $\mathrm{C} / /$ Proceeding ofFirstWorld Conference onStructure Contro1,Los. Angeles, USA. New York: John Wily\& Sons,Ltd, 1994.

[5] Symans M D, Constantiou M C. "Passive Fluid Viscous Damping Systems for Seismic Energy Dissipation" J. Journal of Earthquake Technology, 1998, 4. pp. 185-206.

[6] Fujino Y M. "Design Formulas of Tuned Mass Dampers Based on a Perturbation Technique " J.Earthquake Engineering and Structural Dynamics, 1993, 10. Pp. 833-854.

[7] Zuk W. "Kinetic Structures “ J.Civil Engineering, 1968, 12. Pp. 62-64.

[8] Mei G, Kareem A, Kantor J C. "Real-time Model Predictive Control of Structures under Earthquakes "J. Earthquake Engineering and Structural Dynamics, 2001, 4. Pp. 995-1019.

[9] YangG, SpencerB F Jr,Carlson J D. "Large-scale MR Fluid Dampers:Modeling and Dynamic Performance Considerations"J.Engineering Structures, 2002, 1. Pp. 309-323.

[10] G.Y.Yan. F. Q. Chen. B. N. Sun. "Fuzzy Neural Network Application of high-rise buildings across-wind vibration control" $\mathrm{J}$. Vibration and Shock, 2007, 1. Pp. 69-73. 